\title{
Multimorbidity and co-occurring musculoskeletal pain do not modify the effect of the SELFBACK app on low back pain-related disability
}

Cecilie K. Øverås, ${ }^{1,2^{*}}$ (D) Tom I. L. Nilsen ${ }^{1}$, Barbara I. Nicholl ${ }^{3}$, Guy Rughani ${ }^{3}$, Karen Wood ${ }^{3}$, Karen Søgaard ${ }^{2,4}$, Frances S. Mair ${ }^{3}$ and Jan Hartvigsen ${ }^{2,5}$

\begin{abstract}
Background: SELFBACK, an artificial intelligence (AI)-based app delivering evidence-based tailored self-management support to people with low back pain (LBP), has been shown to reduce LBP-related disability when added to usual care. LBP commonly co-occurs with multimorbidity ( $\geq 2$ long-term conditions) or pain at other musculoskeletal sites, so this study explores if these factors modify the effect of the SELFBACK app or influence outcome trajectories over time.

Methods: Secondary analysis of a randomized controlled trial with 9-month follow-up. Primary outcome is as follows: LBP-related disability (Roland Morris Disability Questionnaire, RMDQ). Secondary outcomes are as follows: stress/depression/illness perception/self-efficacy/general health/quality of life/physical activity/global perceived effect. We used linear mixed models for continuous outcomes and logistic generalized estimating equation for binary outcomes. Analyses were stratified to assess effect modification, whereas control $(n=229)$ and intervention $(n=232)$ groups were pooled in analyses of outcome trajectories.
\end{abstract}

\footnotetext{
*Correspondence: ckoveraas@health.sdu.dk; cecilie.overas@ntnu.no

Frances S. Mair and Jan Hartvigsen shared last authorship.

'Department of Public Health and Nursing, NTNU - Norwegian University of Science and Technology, Trondheim, Norway

${ }^{2}$ Department of Sports Science and Clinical Biomechanics, University of Southern Denmark, Odense, Denmark

Full list of author information is available at the end of the article
}

(C) The Author(s). 2022 Open Access This article is licensed under a Creative Commons Attribution 4.0 International License, which permits use, sharing, adaptation, distribution and reproduction in any medium or format, as long as you give appropriate credit to the original author(s) and the source, provide a link to the Creative Commons licence, and indicate if changes were made. The images or other third party material in this article are included in the article's Creative Commons licence, unless indicated otherwise in a credit line to the material. If material is not included in the article's Creative Commons licence and your intended use is not permitted by statutory regulation or exceeds the permitted use, you will need to obtain permission directly from the copyright holder. To view a copy of this licence, visit http://creativecommons.org/licenses/by/4.0/ The Creative Commons Public Domain Dedication waiver (http://creativecommons.org/publicdomain/zero/1.0/) applies to the data made available in this article, unless otherwise stated in a credit line to the data. 
Results: Baseline multimorbidity and co-occurring musculoskeletal pain sites did not modify the effect of the SELFACK app. The effect was somewhat stronger in people with multimorbidity than among those with LBP only (difference in RMDQ due to interaction, $-0.9[95 \% \mathrm{Cl}-2.5$ to 0.6]). Participants with a greater number of long-term conditions and more co-occurring musculoskeletal pain had higher levels of baseline disability (RMDQ 11.3 for $\geq 2$ long-term conditions vs 9.5 for LBP only; 11.3 for $\geq 4$ musculoskeletal pain sites vs 10.2 for $\leq 1$ additional musculoskeletal pain site); along with higher baseline scores for stress/depression/illness perception and poorer pain self-efficacy/general health ratings. In the pooled sample, LBP-related disability improved slightly less over time for people with $\geq 2$ long-term conditions additional to LBP compared to no multimorbidity and for those with $\geq 4$ co-occurring musculoskeletal pain sites compared to $\leq 1$ additional musculoskeletal pain site (difference in mean change at 9 months $=1.5$ and 2.2, respectively). All groups reported little improvement in secondary outcomes over time.

Conclusions: Multimorbidity or co-occurring musculoskeletal pain does not modify the effect of the selfBACK app on LBP-related disability or other secondary outcomes. Although people with these health problems have worse scores both at baseline and 9 months, the Al-based selfBACK app appears to be helpful for those with multimorbidity or co-occurring musculoskeletal pain.

Trial registration: NCT03798288. Date of registration: 9 January 2019

Keywords: Low back pain, Musculoskeletal pain, Comorbidity, Multimorbidity, Self-management, Telemedicine, Mobile applications, Digital technology, Artificial intelligence, Randomized controlled trial

\section{Background}

Low back pain (LBP) is the leading cause of years lived with disability globally $[1,2]$ and is costly to societies due to sickness absence, lost productivity, and healthcare costs [3]. LBP is commonly accompanied by musculoskeletal (MSK) pain in other body regions [4], and people with LBP and co-occurring MSK pain are more likely to experience persistent and disabling pain with a poorer prognosis than those with LBP alone $[5,6]$. LBP is also a 'component disorder' in multimorbidity [7]. Multimorbidity, the coexistence of two or more longterm conditions (LTCs) [8, 9], is a growing global challenge, with negative impacts on health care utilization [10], mortality [11], and quality of life [12]. Previous studies have found LBP to be associated with a range of other conditions such as anxiety and depressed mood, osteo- and rheumatoid arthritis, cardiovascular disease, diabetes, gastrointestinal, and respiratory disorders [1325]. In primary care, multimorbidity prevalence varies from $<15 \%$ to $>95 \%$ depending on method of measurement, age, socioeconomic status, and gender [26]. Most primary care workload and hospital admissions involve people with multimorbidity [27], and when MSK pain is part of multimorbidity, it increases the impact on physical health and health care costs [28].

LBP guidelines recommend self-management strategies encouraging people to learn about and manage their condition, thereby supporting autonomy and independence $[29,30]$. Advice on self-management may potentially be delivered by digital health interventions (websites, mobile applications, wearable technology) that are seen as scalable and feasible ways to engage care- seekers [31, 32]. However, despite rapid growth [33], the evidence for effectiveness, safety, and appropriateness of digital health interventions to support self-management in LBP remains weak [34].

A multinational randomized controlled trial (RCT) of the SELFBACK digital intervention, designed to deliver evidence-based, individually tailored self-management support for people with LBP through an artificial intelligence (AI)-based app [35, 36], sought to improve the evidence base in this emerging area. The effect of the SELFBACK system on reducing LBP-related disability showed overall small, but statistically significant benefits of the AIbased app when used in addition to usual care [37].

Assessing possible modifiers of effect was listed in the prespecified statistical analysis plan for the main trial. Multimorbidity and co-occurring MSK pain may contribute to a more complex clinical picture and resilience to treatment that could influence the effect of the selfBACK intervention. As part of the trial, data on the presence of LTCs and co-occurring MSK pain were collected, providing a unique opportunity to investigate whether people with multimorbidity and co-occurring MSK pain experience the same intervention effect when compared to those without. Additionally, using the trial population as a cohort allows for the study of trajectories of outcomes over time. Self-management is similarly recommended or even deemed necessary for people with multimorbidity [38], because multiple long-term conditions complicate care needs [39]. To our knowledge, no RCT on digital health interventions for LBP has studied the impact of multimorbidity on the clinical effectiveness of the intervention. 
We aimed to address the following research questions: (1) Is the effect of the SELFBACK system on LBP-related disability, quality of life, stress, depression, general health, illness perception, self-efficacy, physical activity, and global perceived effect, modified by baseline multimorbidity or number of co-occurring MSK pain sites? (2) Are baseline number of LTCs and co-occurring MSK pain sites associated with baseline measures and 9month trajectories of these outcomes?

\section{Methods}

The national ethical committees in Denmark (S20182000-24) and Norway (2017/923-6) approved this trial, and all participants provided written informed consent. The trial is registered with ClinicalTrials.gov (NCT03798288).

\section{Study design, setting, participants and procedures}

This paper presents secondary analyses of a single-blind randomized controlled trial among patients with nonspecific LBP, randomized to two parallel groups to test the SELFBACK system in addition to usual care (intervention arm) versus usual care only (control arm). The protocol for the SELFBACK project and the SELFBACK trial have been published $[35,36]$. The SELFBACK trial was conducted in Trondheim, Norway, and Odense, Denmark. Participants were recruited by physiotherapists, chiropractors, and general practitioners in primary care and from the Spine Centre outpatient spine clinic in Southern Denmark from March to December 2019. In brief, people aged 18 years or older seeking healthcare advice for non-specific LBP of any duration within the preceding 8 weeks that were interested in participating were screened for eligibility. Patients needed to score six or above on the Roland-Morris Disability Questionnaire (RMDQ), have access to a smartphone to install the SELFBACK app, and have an email address to meet inclusion criteria. Exclusion criteria have been described in detail previously [36, 37].

After consenting to participation and completing a baseline questionnaire, block randomization of participants was performed in a web-based trial management system. In addition to usual care, the intervention group had access to the full content of the data-driven SELFBACK system delivered via the AI-based SELFBACK app and a connected physical activity-detecting wristband. Details of the SELFBACK app content and procedures are described in greater detail elsewhere [35]. The app's main elements are educational material, exercises for strength and flexibility, and tracking of physical activity (i.e. step count) detected by the wristband. Based on these three main elements, participants are presented with weekly individually tailored self-management plans to match the participant's health status by case-based reasoning (CBR) technology, a branch of AI. The SELFBACK app provided participants with instant feedback following individually set goals [35] likely to motivate and enhance participation in the trial. Participants in the control arm were asked to continue the care plan from their health care professional and whatever other help they found relevant.

For the first aim in this secondary analysis, the RCT design was used to explore effect modification in analyses stratified by multimorbidity status or number of co-occurring MSK pain sites. For the second aim, the control and intervention group were pooled and analysed according to number of LTCs and MSK pain sites.

\section{Data collection and variables}

All participants completed the baseline web questionnaire at the start of the trial, and the pre-defined outcome variables were assessed at 6 weeks and 3, 6, and 9 months with 3 months as the primary follow-up time point.

Multimorbidity was defined as the coexistence of two or more LTCs (LBP $+\geq 1$ LTC) $[8,9]$, versus no multimorbidity (LBP only). In the pooled sample, we further categorized people according to LTC count (LBP only, 1 LTC, $\geq 2$ LTCs). The LTC variables were drawn from the baseline questionnaire applying questions adapted from the Norwegian HUNT study [40], covering the following categories: mental health issues, osteoarthritis, inflammatory arthritis, gastrointestinal problems, respiratory conditions, cardiovascular conditions, diabetes, neurological, cancer, and other LTCs.

Co-occurring MSK pain was defined as current pain marked on a mannequin with eight MSK pain site options in addition to LBP (neck, shoulders, upper back, elbows, lower back, wrists/hands, hips/thighs, knees, ankles/feet). This pain site mannequin is a modified version of the validated and commonly used standardized Nordic Questionnaire [41]. To assess possible effect modification, co-occurring MSK pain at baseline was classified according to number of sites additional to LBP $(0-1, \geq 2)$. To assess trajectories of outcomes from baseline and over the 9-month trial period in the pooled sample, we classified number of MSK pain sites according to the sample specific distribution of participants $(\mathrm{LBP}+0-1$ pain site, $\mathrm{LBP}+2-3$ pain sites, $\mathrm{LBP}+\geq 4$ pain sites).

The primary outcome was LBP-related disability measured using the RMDQ [42], where higher scores (0-24) indicate higher disability. Secondary outcomes were chosen based on availability of data guided by the recommendations in the Core Outcome Set for Multimorbidity Research (COSmm) [43]. This included healthrelated quality of life (EQ-5D: range 0-100, with higher scores indicating better health status) weighted 
according to Danish value set [44]; Perceived Stress Scale (PSS: range 0-40, where higher scores indicate greater perceived stress) [45]; Patient Health Questionnaire-8 (PHQ-8: 8-question 0-24 point scale, where higher score indicate greater depressive symptoms) [46]; General health (on a 100 point vertical scale, where higher score indicate better health) [47]; The Brief Illness Perception Questionnaire (BIPQ: range 0-10, where higher score indicate more threatening view of the pain) [48]; Pain Self-Efficacy Questionnaire (PSEQ: range $0-60$, where higher scores reflect stronger confidence in ability to cope despite pain) [49]; Saltin-Grimby Physical Activity Level Scale assessing leisure time physical activity (4 levels of intensity collapsed into a binary variable sedentary/some physical activity and regular/ hard physical activity) [50]; and Patient's Global Perceived Effect (GPE: range -5 to 5, where positive scores indicate LBP improvement and negative scores a worsening) [51].

\section{Statistical analysis}

For research question 1, we estimated the effect of the intervention in strata according to multimorbidity status (no multimorbidity vs multimorbidity [LBP $+\geq 1$ LTC]) or number of co-occurring MSK pains sites $(\leq 1$ additional pain site, $\geq 2$ additional pain sites) using a constrained longitudinal data analysis approach, as described in the primary outcome paper [37]. In this approach, a linear mixed model was used for continuous outcomes and a logistic generalized estimating equation (GEE) model for binomial outcomes. Analyses were conducted according to the intention-to-treat principle, including all available data for all participants at each time point as specified in the statistical analysis plan of the main trial. Percentage of complete data at each time point can be found in the main trial paper [37]. Any missing values are inherently accounted for in the mixed model approach. Estimates of effect modification were calculated as the difference in the strata specific effects at 3 and 9 months.

To address research question 2, we presented trajectories of all outcomes from baseline to 6 weeks and 3, 6, and 9 months descriptively as means (SD). We further estimated crude mean changes from baseline to 9 months for all outcomes within categories of baseline multimorbidity status and number of co-occurring pain sites using linear mixed models including the adjusted difference in mean change from baseline between the categories with only LBP at baseline as the common reference. Logistic GEE models estimated odds ratio for physical activity at 3 and 9 months, comparing categories of multimorbidity and number of co-occurring pain sites. We justified pooling of the control and intervention group as the distribution of people with and without multimorbidity and categories of co-occurring MSK pain was evenly distributed due to random allocation among those who received the selfBACK app and not (multimorbidity status: no multimorbidity-only LBP $45.6 \%$ in control and $54.4 \%$ in intervention group; LBP + 1 LTC $56.9 \%$ in control and $43.1 \%$ in intervention group; LBP $+\geq 2$ LTCs $47.0 \%$ in control and $52 \%$ in intervention group; number of co-occurring pain sites: $\mathrm{LBP}+\leq 1$ pain site $46.8 \%$ in control and $53.2 \%$ in intervention group; $L B P+2-3$ pain sites $48.8 \%$ in control and $51.2 \%$ in intervention group; $\mathrm{LBP}+\geq 4$ pain sites $56.2 \%$ in control and $43.8 \%$ in intervention group).

Similar to the main paper [37], all effects were adjusted for variables used for the stratified randomization (i.e. country of recruitment [Denmark, Norway], clinical setting of recruitment [General Practitioner, Physiotherapist, Chiropractor, Outpatient back clinic]) and possible prognostic variables (age [years], sex [female, male], education [< 10 years, $10-12$ years, $>12$ years], duration of current pain episode at baseline $[\leq 4$ weeks, $5-12$ weeks, $>12$ weeks], and average pain intensity in the preceding week at baseline [0-10 scale]. Associations between categories of multimorbidity status and number of cooccurring pain sites (i.e. in the pooled sample) were additionally adjusted for workability index [0-10 scale], BMI $\left[\mathrm{kg} / \mathrm{m}^{2}\right]$, and physical activity level [self-reported four level Saltin-Grimby questionnaire]). The precision of all estimated associations is given by a $95 \%$ confidence interval. All analyses were performed using Stata version 16.1 (StataCorp LLC).

\section{Results}

Among the 461 enrolled and randomly assigned participants, 229 were randomized to usual care (control arm) and 232 randomized to SELFBACK adjunct to usual care (intervention arm). Of the LBP participants, 312 were categorized as having multimorbidity (LBP $+\geq 1 \mathrm{LTC})$ and $271 \mathrm{had} \geq 2$ co-occurring MSK pain sites in addition to LBP respectively. Full details are provided in Fig. 1.

People with multimorbidity were slightly older than those without, and people with multimorbidity or several co-occurring MSK pain sites were more often females, had somewhat higher pain intensity, and lower workability and physical activity levels. The majority had $>12$ years of education (about 65\%), and $60 \%$ had $\geq 12$ weeks of LBP duration with no differences across the groups (Table 1).

The most frequent LTCs were gastrointestinal problems $(31 \%)$ and mental health issues (27\% [depression $18 \%$; anxiety $9 \%]$ ). At baseline, the mean number of LTCs were similar among those in the control and intervention arm (1.33 [SD 1.33] vs 1.32 [SD 1.54]). The most frequent co-occurring MSK pain sites alongside LBP were hips/thighs (45\%). The mean number of co- 


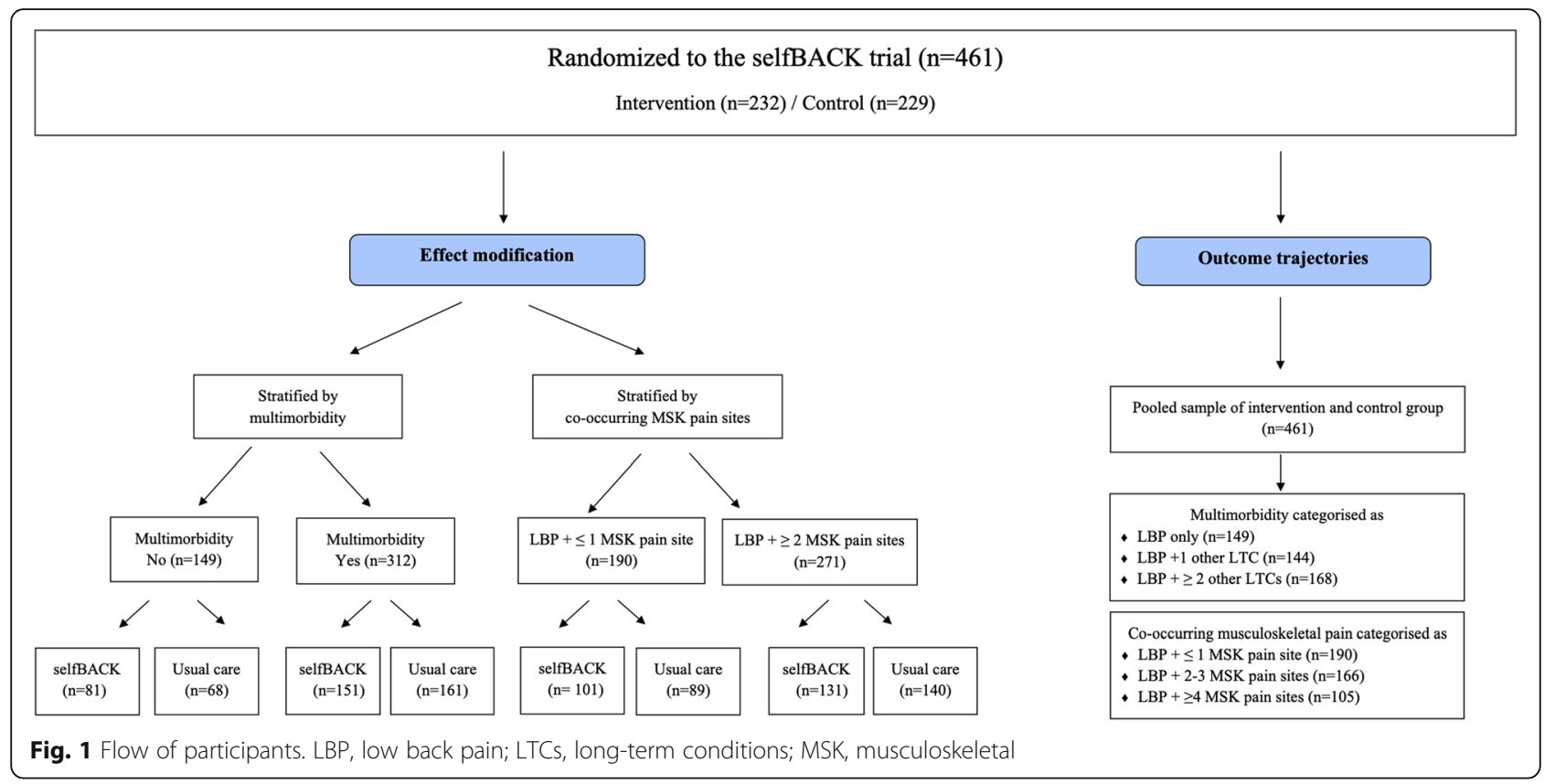

Table 1 Baseline characteristics of the study population, stratified by study arm, multimorbidity status and number of co-occurring MSK pain sites

\begin{tabular}{|c|c|c|c|c|c|c|c|c|}
\hline \multirow[t]{3}{*}{ Variable } & \multicolumn{4}{|c|}{ Multimorbidity } & \multicolumn{4}{|c|}{ No. of co-occurring MSK pain sites } \\
\hline & \multicolumn{2}{|l|}{$\begin{array}{l}\text { No } \\
(n=149)\end{array}$} & \multicolumn{2}{|l|}{$\begin{array}{l}\text { Yes } \\
(n=312)\end{array}$} & \multicolumn{2}{|l|}{$\begin{array}{l}0-1 \\
(n=190)\end{array}$} & \multicolumn{2}{|l|}{$\begin{array}{l}2+ \\
(n=271)\end{array}$} \\
\hline & $\begin{array}{l}\text { Usual care } \\
(n=68)\end{array}$ & $\begin{array}{l}\text { SELFBACK } \\
(n=81)\end{array}$ & $\begin{array}{l}\text { Usual care } \\
(n=161)\end{array}$ & $\begin{array}{l}\text { SELFBACK } \\
(n=151)\end{array}$ & $\begin{array}{l}\text { Usual care } \\
(n=89)\end{array}$ & $\begin{array}{l}\text { SELFBACK } \\
(n=101)\end{array}$ & $\begin{array}{l}\text { Usual care } \\
(n=140)\end{array}$ & $\begin{array}{l}\text { SELFBACK } \\
(n=131)\end{array}$ \\
\hline Age, mean (SD), years & $42.1(13.9)$ & $42.4(13.0)$ & $48.7(14.2)$ & $51.4(15.1)$ & $45.4(15.6)$ & $48.0(14.7)$ & $47.6(13.6)$ & $48.5(15.3)$ \\
\hline Women, \% & 50.0 & 44.4 & 62.1 & 56.3 & 49.4 & 47.5 & 64.3 & 55.7 \\
\hline Education: > 12 years, $\%$ & 61.8 & 69.1 & 64.0 & 63.6 & 66.3 & 72.3 & 61.4 & 60.3 \\
\hline Multimorbidity, \% & - & - & - & - & 34.2 & 35.8 & 65.8 & 64.2 \\
\hline $\begin{array}{l}\text { Co-occurring MSK pain } \\
(2+), \%\end{array}$ & 24.3 & 25.9 & 75.7 & 74.1 & - & - & - & - \\
\hline \multicolumn{9}{|l|}{ Pain duration } \\
\hline$\leq 4$ weeks, $\%$ & 32.3 & 24.7 & 20.5 & 25.1 & 28.1 & 29.7 & 21.5 & 21.4 \\
\hline $5-12$ weeks, \% & 10.3 & 19.8 & 19.3 & 17.9 & 15.7 & 20.8 & 17.1 & 16.8 \\
\hline$>12$ weeks, $\%$ & 57.4 & 55.5 & 60.2 & 57.0 & 56.2 & 49.5 & 61.4 & 61.8 \\
\hline $\begin{array}{l}\text { Pain intensity, mean (SD), } \\
\text { NRS } 0-10\end{array}$ & $4.5(2.0)$ & $4.6(1.9)$ & $5.1(1.8)$ & $5.0(2.0)$ & $4.9(2.0)$ & $4.6(1.9)$ & $5.0(1.8)$ & $5.0(2.0)$ \\
\hline $\begin{array}{l}\text { Work ability index, mean } \\
\text { (SD), } 0-10\end{array}$ & $6.9(1.8)$ & $6.8(2.2)$ & $6.6(1.8)$ & $6.6(1.8)$ & $6.6(1.9)$ & $6.9(2.0)$ & $6.7(1.8)$ & $6.5(1.9)$ \\
\hline $\begin{array}{l}\text { Body mass index, mean } \\
\text { (SD), } \mathrm{kg} / \mathrm{m}^{2}\end{array}$ & $25.9(4.3)$ & $27.3(4.6)$ & $28.6(5.6)$ & $27.4(4.8)$ & $26.5(4.6)$ & $26.9(4.6)$ & $28.6(5.7)$ & $27.7(4.9)$ \\
\hline \multicolumn{9}{|l|}{ Physical activity } \\
\hline $\begin{array}{l}\text { Sedentary/some } \\
\text { physical activity, \% }\end{array}$ & 51.5 & 46.9 & 64.6 & 63.0 & 53.9 & 55.5 & 65.0 & 58.8 \\
\hline $\begin{array}{l}\text { Regular/hard physical } \\
\text { activity, \% }\end{array}$ & 48.6 & 53.1 & 35.4 & 37.0 & 46.1 & 44.5 & 35.0 & 41.2 \\
\hline
\end{tabular}


occurring MSK pain sites was 2.34 (SD 1.8) in the control arm and 2.14 (SD 1.8) for the intervention arm (Fig. 2) (See Additional file 1: Table S1, for further details). There was no reported harm or adverse events by any participants.

\section{Effect modification of the intervention}

Overall, there was no clear evidence that multimorbidity modified the effect of the intervention on any of the outcomes under study. However, the adjusted mean difference in RMDQ score between the intervention and control arms at 3 months showed somewhat greater benefit for people with baseline multimorbidity, than for those without multimorbidity (mean difference due to interaction -0.9 [95\% CI -2.5 to $0.6, p=0.25]$ ), while the effect resolved by 9 months follow-up (mean difference due to interaction 0.2 [95\% CI -1.5 to $1.9, p=$ 0.81]). Having LBP and two or more additional MSK pain sites at baseline did not modify the effect at either three- or nine-month follow-up (Tables 2 and 3, Fig. 3).

\section{Baseline differences and trajectories of outcomes} stratified by LTC count and number of MSK pain sites

Baseline LBP-related disability (RMDQ) was higher for those with multimorbidity (LBP $+\geq 2$ LTCs 11.3; LBP + 1 LTC 10.4; LBP only 9.5), and with more co-occurring MSK pain $(\mathrm{LBP}+\geq 4$ pain sites 11.3 ; $\mathrm{LBP}+\geq 2-3$ pain sites 10.1; $L B P+\leq 1$ pain site 10.2 ). The secondary outcomes at baseline similarly showed higher baseline scores for stress, depression, higher illness perception, poorer pain self-efficacy, and lower general health ratings with more LTCs and co-occurring MSK pain.
Quality of life measured by EQ5D was similar across the groups at baseline (Additional file 1: Table S2 and S3).

RMDQ gradually improved over time for all groups. However, participants with $\geq 2$ LTCs experienced less reduction when compared to those with no or only one LTC in addition to LBP (adjusted mean difference at 9 months 1.5 [95\% CI 0.5 to 2.5]). Similarly, for those with co-occurring MSK pain sites we saw that those with LBP and $\geq 4$ pain sites improved less compared to those with fewer co-occurring pain sites (difference between groups 2.2 [95\% CI 1.1 to 3.3 ] at 9 months).

For the secondary outcomes, all groups reported minimal improvement for all outcomes at all time points. Those with no LTCs and LBP with only $0-1$ additional MSK pain site improved most on measures of stress, depression, and general health, while those with LBP and two or more LTCs and four or more additional MSK pain sites had less improvement of illness perception, self-efficacy, and the global perceived effect (see Additional file 1: Table S2 and S3, for details). For the health-related quality of life (EQ5D), the minimal improvements over time were similar across all groups. Those without LTCs and least co-occurring MSK pain were more physically active at baseline based on selfreported measures in the Saltin-Grimby questionnaire; with no change over the project period (Additional file 1: Table S4).

\section{Discussion}

This secondary analysis showed that across different outcomes including LBP-related disability, the effect of the SELFBACK intervention was similar regardless of baseline

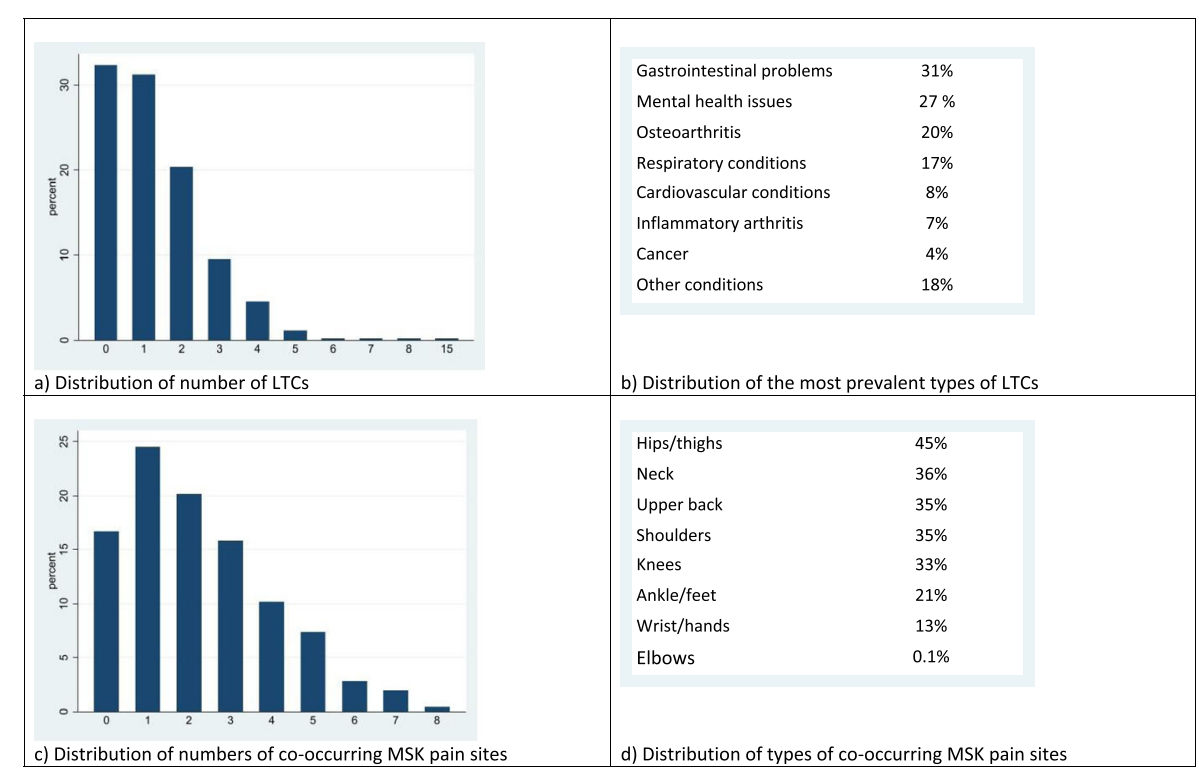

Fig. 2 Distributions of number and types of LTCS and co-occurring MSK pain sites at baseline. LTCs, long-term conditions; MSK, musculoskeletal 
Table 2 Effect of the SELFBACK system on RMDQ and other core outcomes, stratified by multimorbidity status

\begin{tabular}{|c|c|c|c|c|c|c|c|}
\hline \multirow[b]{3}{*}{ Outcome } & \multicolumn{3}{|c|}{ No multimorbidity (LBP only) } & \multicolumn{3}{|c|}{ Multimorbidity (LBP $+\geq 1$ LTC) } & \multirow[b]{3}{*}{$P_{\text {interaction }}$} \\
\hline & \multicolumn{3}{|c|}{ Mean (SD) ${ }^{\mathrm{a}}$} & \multicolumn{3}{|c|}{ Mean (SD) ${ }^{\mathrm{a}}$} & \\
\hline & $\begin{array}{l}\text { Usual care } \\
(n=68)\end{array}$ & $\begin{array}{l}\text { SELFBACK } \\
(n=81)\end{array}$ & $\begin{array}{l}\text { Adjusted }^{\mathrm{b}} \text { mean } \\
\text { difference }(95 \% \mathrm{Cl})\end{array}$ & $\begin{array}{l}\text { Usual care } \\
(n=161)\end{array}$ & $\begin{array}{l}\text { SELFBACK } \\
(n=151)\end{array}$ & $\begin{array}{l}\text { Adjusted }^{\mathrm{b}} \text { mean } \\
\text { difference }(95 \% \mathrm{Cl})\end{array}$ & \\
\hline \multicolumn{8}{|l|}{ RMDQ (0-24) } \\
\hline Baseline & $9.5(4.4)$ & & & $10.9(4.4)$ & & & \\
\hline 3 months & $5.7(4.5)$ & $5.7(4.8)$ & $-0.1(-1.4$ to 1.2$)$ & $8.2(5.5)$ & $7.2(4.7)$ & $-1.0(-1.9$ to -0.2$)$ & 0.25 \\
\hline 9 months & $5.1(4.5)$ & $4.3(4.9)$ & $-0.9(-2.3$ to 0.5$)$ & $7.6(5.8)$ & $6.9(5.3)$ & $-0.8(-1.7$ to 0.1$)$ & 0.81 \\
\hline \multicolumn{8}{|l|}{ EQ-5D (0-1) } \\
\hline Baseline & $0.72(0.14)$ & & & $0.69(0.12)$ & & & \\
\hline 3 months & $0.78(0.10)$ & $0.77(0.13)$ & $-0.00(-0.04$ to 0.03$)$ & $0.73(0.14)$ & $0.75(0.11)$ & $0.02(-0.0$ to 0.05$)$ & 0.25 \\
\hline 9 months & $0.82(0.12)$ & $0.83(0.10)$ & $0.01(-0.03$ to 0.06$)$ & $0.73(0.14)$ & $0.76(0.13)$ & 0.03 (0.0 to 0.05$)$ & 0.66 \\
\hline \multicolumn{8}{|l|}{ PSS (0-40) } \\
\hline Baseline & $13.9(6.9)$ & & & $15.36(6.8)$ & & & \\
\hline 3 months & $13.8(6.8)$ & $12.6(6.3)$ & $-1.1(-2.8$ to 0.6$)$ & $15.2(7.3)$ & $14.5(7.3)$ & $-0.6(-1.7$ to 0.6$)$ & 0.68 \\
\hline 9 months & $11.6(6.5)$ & $11.0(5.7)$ & $-0.5(-2.3$ to 1.3$)$ & $14.7(7.1)$ & $13.0(7.5)$ & $-1.6(-2.8$ to -0.4$)$ & 0.28 \\
\hline \multicolumn{8}{|l|}{ PHQ-8 (0-24) } \\
\hline Baseline & $5.7(4.6)$ & & & $6.8(4.2)$ & & & \\
\hline 3 months & $5.1(4.3)$ & $5.1(4.3)$ & $0.1(-1.0$ to 1.1$)$ & $6.8(4.6)$ & $6.1(4.6)$ & $-0.6(-1.3$ to 0.1$)$ & 0.31 \\
\hline 9 months & $4.2(4.4)$ & $4.3(3.6)$ & $0.1(-1.0$ to 1.3$)$ & $6.6(4.9)$ & $5.5(4.4)$ & $-1.0(-1.8$ to -0.2$)$ & 0.10 \\
\hline \multicolumn{8}{|c|}{ General health $(0-100)$} \\
\hline Baseline & $69.3(16.1)$ & & & $64.7(16.5)$ & & & \\
\hline 3 months & 74.4 (15.6) & 70.9(18.9) & $-3.0(-8.1$ to 2.0$)$ & $69.0(17.8)$ & 70.9 (15.9) & $1.8(-1.5$ to 5.1$)$ & 0.10 \\
\hline 9 months & $78.5(12.9)$ & $77.7(16.4)$ & $-0.6(-6.0$ to 4.8$)$ & $69.0(18.5)$ & $71.4(15.7)$ & $2.2(-1.2$ to 5.6$)$ & 0.39 \\
\hline \multicolumn{8}{|l|}{ BIPQ (0-80) } \\
\hline Baseline & $42.0(11.0)$ & & & $45.0(10.7)$ & & & \\
\hline 3 months & $37.9(13.0)$ & $34.7(15.4)$ & $-3.3(-6.8$ to 0.2$)$ & $41.5(13.5)$ & $36.3(13.6)$ & $-5.0(-7.2$ to -2.9$)$ & 0.39 \\
\hline 9 months & $33.4(17.2)$ & $32.9(12.6)$ & $-0.6(-4.4$ to 3.1$)$ & $40.0(13.3)$ & $34.7(15.8)$ & $-5.2(-7.4$ to -2.9$)$ & 0.04 \\
\hline \multicolumn{8}{|l|}{ PSEQ (0-60) } \\
\hline Baseline & $45.4(10.7)$ & & & $43.5(11.2)$ & & & \\
\hline 3 months & $48.9(9.4)$ & $50.7(9.3)$ & $1.8(-0.7$ to 4.4$)$ & $45.6(11.6)$ & $48.4(10.2)$ & 2.7 (1.0 to 4.5$)$ & 0.57 \\
\hline 9 months & $48.9(8.7)$ & $52.7(7.5)$ & 3.8 (1.0 to 6.5 ) & $46.0(11.5)$ & $49.1(10.3)$ & 2.9 (1.1 to 4.8$)$ & 0.59 \\
\hline \multicolumn{8}{|l|}{ GPE (- 5 to 5$)$} \\
\hline 3 months & $1.5(2.1)$ & $1.9(1.9)$ & $0.4(-0.2$ to 1.1$)$ & $1.2(1.8)$ & $2.0(1.9)$ & 0.8 (0.3 to 1.2$)$ & 0.35 \\
\hline \multirow[t]{2}{*}{9 months } & $2.0(2.4)$ & $2.4(1.9)$ & $0.5(-0.2$ to 1.2$)$ & $1.1(2.1)$ & $2.1(2.0)$ & $0.9(0.5$ to 1.4$)$ & 0.27 \\
\hline & Odds ratio & & & & & & \\
\hline \multicolumn{8}{|l|}{ PA } \\
\hline Baseline & - & - & & & & & \\
\hline 3 months & 0.85 & 0.85 & 0.98 (0.53 to 1.84$)$ & 1.07 & 0.83 & 0.78 (0.50 to 1.21$)$ & 0.55 \\
\hline 9 months & 0.86 & 0.95 & 1.11 (0.56 to 2.22 ) & 1.01 & 1.19 & 1.19 (0.72 to 1.94$)$ & 0.84 \\
\hline
\end{tabular}

Abbreviations: RMDQ Roland Morris Disability Questionnaire, $L B P$ low back pain, $L T C s$ long-term conditions, $S D$ standard deviation, $E Q-5 D$ health-related quality of life, PSS Perceived Stress Scale, PHQ-8 Patient Health Questionnaire-8, BIPQ The Brief Illness Perception Questionnaire, PSEQ Pain Self-Efficacy Questionnaire, GPE Patient's Global Perceived Effect, $P A$ physical activity

${ }^{a}$ Marginal means from a crude linear mixed model, and SDs from raw data among persons with information at the specific time points

${ }^{b}$ Adjusted for country, recruiting clinician, education $(<10,10-12,>12$ years), pain duration at baseline $(\leq 4,5-12,>12$ weeks), pain intensity as baseline $(0-10$ scale), sex (female vs male), and age (years) 
Table 3 Effect of the selfBACK system on RMDQ and other core outcomes, stratified by number of co-occurring MSK pain sites

\begin{tabular}{|c|c|c|c|c|c|c|c|}
\hline \multirow[t]{3}{*}{ Outcome } & \multicolumn{3}{|c|}{$0-1$ co-occurring pain sites (LBP $+\leq 1$ MSK pain site) } & \multicolumn{4}{|c|}{$2+$ co-occurring pain sites (LBP $+\geq 2$ MSK pain sites) } \\
\hline & \multicolumn{3}{|c|}{ Mean (SD) ${ }^{\mathrm{a}}$} & \multicolumn{3}{|c|}{ Mean (SD) $)^{a}$} & \multirow[b]{2}{*}{$P_{\text {interaction }}$} \\
\hline & $\begin{array}{l}\text { Usual care } \\
(n=89)\end{array}$ & $\begin{array}{l}\text { SELFBACK } \\
(n=101)\end{array}$ & $\begin{array}{l}\text { Adjusted }{ }^{\mathrm{b}} \text { mean } \\
\text { difference }(95 \% \mathrm{Cl})\end{array}$ & $\begin{array}{l}\text { Usual care } \\
(n=140)\end{array}$ & $\begin{array}{l}\text { SELFBACK } \\
(n=131)\end{array}$ & $\begin{array}{l}\text { Adjusted }{ }^{\mathrm{b}} \text { mean } \\
\text { difference }(95 \% \mathrm{Cl})\end{array}$ & \\
\hline \multicolumn{8}{|l|}{ RMDQ (0-24) } \\
\hline Baseline & $10.2(4.4)$ & & & $10.6(4.4)$ & & & \\
\hline 3 months & $6.8(5.0)$ & $6.2(4.5)$ & $-0.4(-1.6$ to 0.7$)$ & $7.8(5.6)$ & $7.0(4.9)$ & $-0.9(-1.9$ to 0.0$)$ & 0.57 \\
\hline 9 months & $6.1(5.1)$ & $5.1(4.5)$ & $-0.8(-2.0$ to 0.4$)$ & $7.3(5.8)$ & $6.7(5.7)$ & $-0.7(-1.7$ to 0.3$)$ & 0.82 \\
\hline \multicolumn{8}{|l|}{ EQ-5D (0-1) } \\
\hline Baseline & $0.71(0.15)$ & & & $0.70(0.11)$ & & & \\
\hline 3 months & $0.76(0.13)$ & $0.78(0.12)$ & $0.01(-0.03$ to 0.04$)$ & $0.73(0.13)$ & $0.74(0.11)$ & $0.02(-0.01$ to 0.04$)$ & 0.71 \\
\hline 9 months & $0.78(0.15)$ & $0.80(0.12)$ & $0.02(-0.02$ to 0.05$)$ & $0.74(0.13)$ & $0.77(0.13)$ & $0.03(-0.00$ to 0.05$)$ & 0.71 \\
\hline \multicolumn{8}{|l|}{ PSS (0-40) } \\
\hline Baseline & $13.8(6.5)$ & & & $15.6(7.0)$ & & & \\
\hline 3 months & $13.4(6.7)$ & $12.3(6.4)$ & $-0.7(-2.2$ to 0.8$)$ & $15.7(7.3)$ & $15.0(7.3)$ & $-0.7(-1.9$ to 0.5$)$ & 0.98 \\
\hline 9 months & $12.4(6.6)$ & $10.9(6.6)$ & $-1.2(-2.8$ to 0.4$)$ & $14.7(7.3)$ & $13.4(7.3)$ & $-1.3(-2.6$ to -0.0$)$ & 0.88 \\
\hline \multicolumn{8}{|l|}{ PHQ-8 (0-24) } \\
\hline Baseline & $5.5(4.0)$ & & & $7.0(4.5)$ & & & \\
\hline 3 months & $5.0(3.9)$ & $4.7(3.7)$ & $-0.2(-1.1$ to 0.7$)$ & $7.0(4.9)$ & $6.5(4.9)$ & $-0.5(-1.3$ to 0.3$)$ & 0.62 \\
\hline 9 months & $4.7(4.9)$ & $4.1(3.7)$ & $-0.3(-1.3$ to 0.6$)$ & $6.6(4.8)$ & $5.8(4.6)$ & $-0.9(-1.7$ to -0.0$)$ & 0.43 \\
\hline \multicolumn{8}{|c|}{ General health (0-100) } \\
\hline Baseline & $68.7(15.4)$ & & & $64.4(17.0)$ & & & \\
\hline 3 months & $71.3(18.4)$ & $71.6(17.3)$ & $-0.0(-4.2$ to 4.2$)$ & $70.0(16.9)$ & $70.5(16.6)$ & $0.8(-2.9$ to 4.4$)$ & 0.73 \\
\hline 9 months & $72.9(18.3)$ & $77.1(14.7)$ & $3.6(-0.8$ to 8.1$)$ & $71.1(17.7)$ & $70.7(17.0)$ & $0.0(-3.8$ to 3.9$)$ & 0.27 \\
\hline \multicolumn{8}{|l|}{ BIPQ (0-80) } \\
\hline Baseline & $43.5(11.3)$ & & & $44.4(10.5)$ & & & \\
\hline 3 months & $39.8(13.9)$ & $35.9(14.1)$ & $-3.7(-6.6$ to -0.8$)$ & $40.8(13.3)$ & $35.7(14.3)$ & $-5.3(-7.7$ to -2.8$)$ & 0.41 \\
\hline 9 months & $37.9(16.3)$ & $32.8(13.7)$ & $-4.8(-7.8$ to -1.8$)$ & $38.1(14.0)$ & $35.1(15.8)$ & $-3.2(-5.7$ to -0.7$)$ & 0.45 \\
\hline \multicolumn{8}{|l|}{ PSEQ (0-60) } \\
\hline Baseline & $45.2(10.9)$ & & & $43.3(11.1)$ & & & \\
\hline 3 months & $47.2(11.4)$ & $50.0(9.1)$ & 2.4 (0.2 to 4.7$)$ & $46.1(11.0)$ & $48.6(10.5)$ & 2.5 (0.6 to 4.5$)$ & 0.99 \\
\hline 9 months & $47.8(10.9)$ & $51.9(8.3)$ & 3.7 (1.3 to 6.1$)$ & $46.3(11.1)$ & $49.0(10.4)$ & $2.8(0.8$ to 4.9$)$ & 0.57 \\
\hline \multicolumn{8}{|l|}{ GPE (- 5 to 5 ) } \\
\hline 3 months & $1.4(2.1)$ & $2.0(2.0)$ & 0.7 (0.1 to 1.3$)$ & $1.2(1.8)$ & $1.9(1.8)$ & 0.7 (0.2 to 1.2$)$ & 0.85 \\
\hline \multirow[t]{2}{*}{9 months } & $1.5(2.2)$ & $2.5(1.9)$ & 1.1 (0.5 to 1.7$)$ & $1.3(2.2)$ & $1.9(2.1)$ & 0.6 (0.1 to 1.1$)$ & 0.26 \\
\hline & Odds ratio & & & & & & \\
\hline \multicolumn{8}{|l|}{ PA } \\
\hline Baseline & - & - & & - & - & & \\
\hline 3 months & 1.03 & 0.83 & 0.82 (0.47 to 1.43 ) & 0.96 & 0.85 & 0.89 (0.55 to 1.44$)$ & 0.80 \\
\hline 9 months & 0.78 & 0.82 & 1.09 (0.61 to 1.97$)$ & 1.09 & 1.37 & $1.29(0.75$ to 2.21$)$ & 0.65 \\
\hline
\end{tabular}

Abbreviations: $R M D Q$ Roland Morris Disability Questionnaire, $M S K$ musculoskeletal, $L B P$ low back pain, $S D$ standard deviation, EQ-5D health-related quality of life, PSS Perceived Stress Scale, $P H Q-8$ Patient Health Questionnaire-8, BIPQ The Brief Illness Perception Questionnaire, PSEQ Pain Self-Efficacy Questionnaire, GPE Patient's Global Perceived Effect, $P A$ physical activity

${ }^{a}$ Marginal means from a crude linear mixed model, and SDs from raw data among persons with information at the specific time points

${ }^{b}$ Adjusted for country, recruiting clinician, education $(<10,10-12,>12$ years), pain duration at baseline $(\leq 4,5-12,>12$ weeks), pain intensity as baseline ( $0-10$ scale), sex (female vs male), and age (years)

multimorbidity or co-occurring MSK pain status. In the pooled sample, those with multimorbidity and cooccurring MSK pain at baseline had slightly higher RMDQ score, and higher scores for stress and depression, as well as lower scores for illness perception, self-efficacy, and general health, when compared to those with no multimorbidity and fewer sites of co-occurring MSK pain. Participants with multimorbidity and co-occurring MSK pain all gradually improved in LBP-related disability over time with no difference between subgroups. 


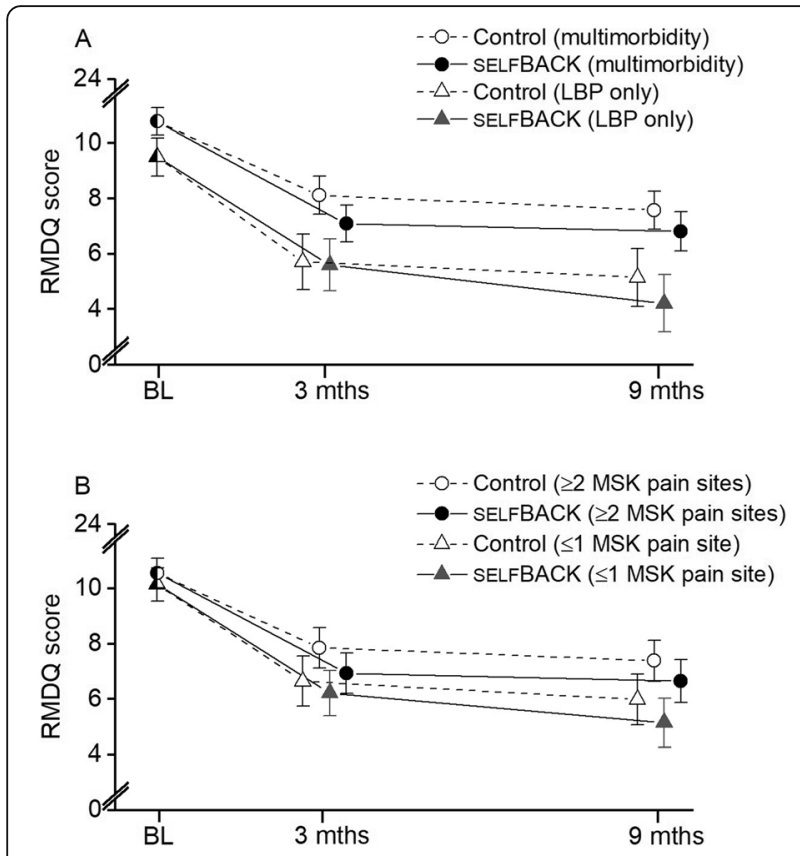

Fig. 3 RMDQ scores and improvement at all time points for participants with and without multimorbidity and co-occurring MSK pain. RMDQ, Roland Morris Disability Questionnaire; MSK, musculoskeletal; LBP, low back pain

The fact that multimorbidity and co-occurring MSK pain did not modify the effect of the SELFBACK intervention may indicate that the SELFBACK system and potentially digital health interventions more broadly could be effective as a supplement to usual care regardless of health condition status. This aligns with a recent metaanalysis that proposed a positive role for mHealth-based self-management programs for persistent LBP [52]. Still, we expected weaker effect of the intervention among people with multimorbidity and co-occurring MSK pain. There could be several factors that explains why this was not observed in our data. It is plausible that the SELFBACK system may enhance the capacity of people with multimorbidity to self-manage, lessening perceived treatment burden [53]. Closer personalized monitoring may be the essence that overrides the additional burden of engaging in multiple treatments and digital health barriers felt by some with multimorbidity [54]. Several behavioural change techniques like goal setting, getting feedback on the outcome, self-monitoring, coping planning, and development of autonomy that are highlighted in the literature [55-57] are integrated in the SELFBACK app, and these may be critical elements that help people with LBP, co-occurring MSK pain and multimorbidity to self-manage. In addition, the fact that the advice is regarded as trustworthy and validated by health-care professionals could facilitate the use of LBP digital health interventions [58].
Our findings that adults with multimorbidity and cooccurring MSK pain experience more adverse effects at baseline than those without also aligns with previous literature which has shown that such individuals generally report higher levels of disability $[4,6,59,60]$, mental health problems [61-63], poorer workability [6, 7, 64, 65], physical inactivity, and obesity $[5,66,67]$. With this complex clinical picture and the cumulative burden of all these conditions, it is not surprising that people with multimorbidity also report higher illness perception, poorer pain self-efficacy, and lower general health. Lower socioeconomic status is associated with poorer health outcomes [68] and a lower level of education is associated with higher likelihood of multimorbidity [69]. However, in this study, about $65 \%$ of participants reported more than 12 years of education, perhaps reflecting the characteristics of people that health-care professionals chose to refer as potential participants to a trial. Hence generalizing to people with other health and social profiles should be undertaken with caution.

\section{Strengths and limitations}

A major strength of this analysis is the inclusion of a range of LTCs, nine MSK pain sites, and outcome measures matching the international experts' consensus on important core outcomes for multimorbidity intervention studies [43]. People with multimorbidity are often excluded from trials [70], so a key strength of this study was the inclusion of such a large proportion of people with multimorbidity, which broadens the applicability of the findings to the wider population seen in everyday clinical practice. Additionally, interventions for multimorbidity integrated within the healthcare system are suggested to be more effective but seldom evaluated [71]. Importantly, participants ranged in age from 18 to 86 years which is unusual for digital health interventions which typically exclude older adults [34].

Despite the relatively large sample included in the main RCT, the study was not powered for robust secondary analyses. The results may therefore be prone to random error and should be viewed as hypothesisgenerating findings that need further examination in future studies. Moreover, all participants with multimorbidity and other MSK pain issues were eligible for inclusion, but it is still possible that health-care professionals may have selected individuals they considered more suitable for the trial, resulting in the inclusion of those who have greater digital health literacy or healthier individuals with multimorbidity and MSK pain. Another limitation was that diseases were self-reported and not clinically confirmed diagnoses, and we do not know anything about the severity of the conditions and whether some of them may be more significant in relation to LBP. We further counted LBP as one LTC when 
considering effect modification stratified by multimorbidity status as LBP commonly features in multimorbidity clusters [72], but this could be a weakness as about $25 \%$ reported a pain duration of $\leq 4$ weeks. Our justification was that these participants most likely have persistent fluctuating LBP [73] which still fits within a LTC definition. Additionally, care-seekers tend to have recurrent LBP with a higher impact score [74], and hence possibly those experiencing their first episode of acute LBP were less likely to be referred into the trial.

\section{Implications and future research}

This study shows that while people with multimorbidity or co-occurring musculoskeletal pain had greater pain related disability at baseline, this did not markedly modify the effects of the selfBACK app. Although the results of this subgroup analyses have limited statistical power, they do not indicate any large differences or harmful effects of the intervention. This has important implications for clinical practice as it suggests that people with LBP and additional long-term conditions or co-occurring MSK pain at other parts of the body could be encouraged to engage with such individually tailored digitally supported self-management interventions as it is possible that they will improve wellbeing.

Future research on AI-based mHealth relating to LBP and self-management could include multimorbidity and other MSK pain sites in the AI algorithms for tailoring advice, support, and exercises. It could further target modifiable risk factors that these conditions have in common [75]. An app that supports self-management of the range of LTCs that someone lives with may be a person-centred and time-efficient approach. Furthermore, as multimorbidity is not limited to older adults $[76,77]$, future trials should, as in this trial, investigate if mHealth can support care across age spans due to essential issues around workability, quality of life, and healthcare costs savings [75]. Importantly, frailty often coexists with multimorbidity, especially in more socioeconomically deprived populations $[78,79]$, and the risk of disability is greater in such individuals. Therefore, future research should consider the applicability of digital selfmanagement interventions for participants affected by frailty (with or without co-existing multimorbidity).

This study followed up people over 9 months, which is longer than most digital health studies targeting those with LBP; however, the longer sustainability of such interventions merits investigation [34]. The process evaluation of the SELFBACK app will provide us with further information about user experiences, including barriers and facilitators to normalization of such interventions into everyday life [80]. Such additional insights will enhance our understanding of the implications of mHealth in the long-term management of people with LBP and multimorbidity. We need better insights to what different people consider a worthwhile effect for an easily accessible digital health intervention with limited risk such as the SELFBACK app, until then it is uncertain whether the results are clinically meaningful for all.

\section{Conclusions}

The effect of the SELFBACK app was similar across a range of outcomes regardless of baseline multimorbidity or co-occurring MSK pain, suggesting that personalized AI-based apps for self-management of LBP can be considered in addition to usual care for those with multimorbidity or co-occurring MSK pain. The more complex the clinical picture and the larger the cumulative burden of additional LTCs or MSK pain, the more affected the participants were at baseline. However, multimorbidity did not affect the course of LBP as all subgroups gradually improved levels of LBP-related disability over time.

\section{Abbreviations \\ LBP: Low back pain; MSK: Musculoskeletal; LTCs: Long-term conditions; RCT: Randomized controlled trial; Al: Artificial intelligence; RMDQ: Roland- Morris Disability Questionnaire; CBR: Case-based reasoning technology; EQ- 5D: Health-related quality of life; PSS: Perceived stress scale; PHQ-8: Patient Health Questionnaire-8 (depression); BIPQ: The Brief Illness Perception Questionnaire; PSEQ: Pain Self-Efficacy Questionnaire; GEE: Generalized estimating equation}

\section{Supplementary Information}

The online version contains supplementary material available at https://doi. org/10.1186/s12916-022-02237-z.

Additional file 1: Tables S1-S4. Table S1 - Baseline multimorbidity and co-occurring pain in study population. Table $\mathbf{S 2}$ - Baseline multimorbidity and change for outcomes for all participants in the SELFBACK trial. Table S3 - Baseline numbers of co-occurring MSK pain sites and change for outcomes for all participants in the SELFBACK trial. Table S4 Odds ratio for an increase in physical activity as assessed by the four-level Saltin-Grimby questionnaire.

\section{Acknowledgements}

Not applicable.

\begin{abstract}
Authors' contributions
CKØ, TILN, BIN, KW, KS, FSM, and JH were involved in the conception of this study and contributed to the study design. Statistical analyses were carried out by TILN and CKØ. TILN had full access to all the data in the study and takes responsibility for the integrity of the data and the accuracy of the data analysis. Interpretation of data was done by CKס, TILN, BIN, RG, KW, KS, FSM, and JH. CKØ drafted the manuscript with critical revision and contribution from all the authors. FSM and JH shared last/senior authorship. All authors have given their approval prior to publication of the final version of this paper.
\end{abstract}

\section{Funding}

This project has received funding from the European Union Horizon 2020 research and innovation programme under grant agreement No. 689043.

\section{Availability of data and materials}

The data that support the findings of this study are available from Professor Paul Jarle Mork (paul.mork@ntnu.no) at the Norwegian University of Science and Technology (NTNU). 


\section{Declarations}

\section{Ethics approval and consent to participate}

The SELFBACK trial was approved by the Danish Data Protection Agency and regional ethics committees in Denmark and Norway. All potential participants provided written informed consent before enrolment into the trial.

\section{Consent for publication}

Not applicable.

\section{Competing interests}

All authors declare no competing interests.

\section{Author details}

'Department of Public Health and Nursing, NTNU - Norwegian University of Science and Technology, Trondheim, Norway. ${ }^{2}$ Department of Sports Science and Clinical Biomechanics, University of Southern Denmark, Odense, Denmark. ${ }^{3}$ Institute of Health and Wellbeing, University of Glasgow, Glasgow, UK. ${ }^{4}$ Department of Clinical Research, University of Southern Denmark, Odense, Denmark. ${ }^{5}$ Chiropractic Knowledge Hub, University of Southern Denmark, Odense, Denmark.

Received: 13 September 2021 Accepted: 4 January 2022 Published online: 08 February 2022

\section{References}

1. Hurwitz EL, Randhawa K, Yu H, Côté P, Haldeman S. The Global Spine Care Initiative: a summary of the global burden of low back and neck pain studies. Eur Spine J. 2018;27:796-801. https://doi.org/10.1007/s00586-0175432-9.

2. GBD 2019 Diseases and Injuries Collaborators. Global burden of 369 diseases and injuries in 204 countries and territories, 1990-2019: a systematic analysis for the Global Burden of Disease Study 2019. Lancet. 2020;396:1204-22. https://doi.org/10.1016/s0140-6736(20)30925-9.

3. Hartvigsen J, Hancock MJ, Kongsted A, Louw Q, Ferreira ML, Genevay S, et al. What low back pain is and why we need to pay attention. Lancet. 2018;391:2356-67. https://doi.org/10.1016/s0140-6736(18)30480-x.

4. Øverås CK, Johansson MS, de Campos TF, Ferreira ML, Natvig B, Mork PJ, et al. Distribution and prevalence of musculoskeletal pain co-occurring with persistent low back pain: a systematic review. BMC Musculoskelet Disord. 2021;22:91. https://doi.org/10.1186/s12891-020-03893-z.

5. Hartvigsen J, Natvig B, Ferreira M. Is it all about a pain in the back? Best Pract Res Clin Rheumatol. 2013;27:613-23. https://doi.org/10.1016/j.berh.2 013.09.008.

6. Coggon D, Ntani G, Walker-Bone K, Palmer KT, Felli VE, Harari R, et al. Epidemiological differences between localized and nonlocalized low back pain. Spine (Phila Pa 1976). 2017(42):740-7. https://doi.org/10.1097/BRS. 0000000000001956.

7. Duffield SJ, Ellis BM, Goodson N, Walker-Bone K, Conaghan PG, Margham T, et al. The contribution of musculoskeletal disorders in multimorbidity: implications for practice and policy. Best Pract Res Clin Rheumatol. 2017; 31(2):129-44. https://doi.org/10.1016/j.berh.2017.09.004

8. Boyd CM, Fortin M. Future of multimorbidity research: how should understanding of multimorbidity inform health system design? Pub Health Rev. 2010;32:451-74. https://doi.org/10.1007/BF03391611.

9. Academy of Medical Sciences. Multimorbidity: a priority for global health research. London: Academy of Medical Sciences; 2018.

10. Palladino R, Tayu Lee J, Ashworth M, Triassi M, Millett C. Associations between multimorbidity, healthcare utilisation and health status: evidence from 16 European countries. Age Ageing. 2016;45:431-5. https://doi.org/10.1 093/ageing/afw044.

11. Jani BD, Hanlon P, Nicholl BI, McQueenie R, Gallacher KI, Lee D, et al. Relationship between multimorbidity, demographic factors and mortality: findings from the UK Biobank cohort. BMC Med. 2019;17:74. https://doi. org/10.1186/s12916-019-1305-x.

12. Fortin M, Lapointe $L$, Hudon C, Vanasse A, Ntetu AL, Maltais D. Multimorbidity and quality of life in primary care: a systematic review. Health Qual Life Outcomes. 2004;2:51. https://doi.org/10.1186/1477-752 5-2-51.
13. Hestbaek L, Leboeuf-Yde C, Manniche C. Is low back pain part of a general health pattern or is it a separate and distinctive entity? A critical literature review of comorbidity with low back pain. J Manip Physiol Ther. 2003;26: 243-52. https://doi.org/10.1016/s0161-4754(03)00003-4

14. Hagen EM, Svensen E, Eriksen HR, Ihlebaek CM, Ursin H. Comorbid subjective health complaints in low back pain. Spine (Phila Pa 1976). 2006(31):1491-5. https://doi.org/10.1097/01.brs.0000219947.71168.08.

15. Smith MD, Russell A, Hodges PW. Do incontinence, breathing difficulties, and gastrointestinal symptoms increase the risk of future back pain? J Pain. 2009;10:876-86. https://doi.org/10.1016/j.jpain.2009.03.003.

16. Smith MD, Russell A, Hodges PW. How common is back pain in women with gastrointestinal problems? Clin J Pain. 2008;24:199-203. https://doi. org/10.1097/AJP.0b013e31815d3601.

17. Gore M, Sadosky A, Stacey BR, Tai KS, Leslie D. The burden of chronic low back pain: clinical comorbidities, treatment patterns, and health care costs in usual care settings. Spine (Phila Pa 1976). 2012(37):E668-77. https://doi. org/10.1097/BRS.0b013e318241e5de.

18. Baykara RA, Bozgeyik Z, Akgul O, Ozgocmen S. Low back pain in patients with rheumatoid arthritis: clinical characteristics and impact of low back pain on functional ability and health related quality of life. J Back Musculoskelet Rehabil. 2013;26:367-74. https://doi.org/10.3233/bmr-130393.

19. Bener A, Verjee M, Dafeeah EE, Falah O, Al-Juhaishi T, Schlogl J, et al. Psychological factors: anxiety, depression, and somatization symptoms in low back pain patients. J Pain Res. 2013;6:95-101. https://doi.org/10.2147/ jpr.S40740.

20. Ferreira PH, Beckenkamp P, Maher CG, Hopper JL, Ferreira ML. Nature or nurture in low back pain? Results of a systematic review of studies based on twin samples. Eur J Pain. 2013;17:957-71. https://doi.org/10.1002/j.1 532-2149.2012.00277.x.

21. Panagopoulos J, Hancock MJ, Kongsted A, Hush J, Kent P. Does anterior trunk pain predict a different course of recovery in chronic low back pain? Pain. 2014;155:977-82. https://doi.org/10.1016/j.pain.2014.01.023.

22. Beeckmans N, Vermeersch A, Lysens R, Van Wambeke P, Goossens N, Thys T, et al. The presence of respiratory disorders in individuals with low back pain: a systematic review. Man Ther. 2016;26:77-86. https://doi.org/10.1016/j. math.2016.07.011.

23. Fernandez M, Ordoñana JR, Hartvigsen J, Ferreira ML, Refshauge KM, Sánchez-Romera JF, et al. Is chronic low back pain associated with the prevalence of coronary heart disease when genetic susceptibility is considered? A co-twin control study of Spanish twins. PLoS One. 2016;11: e0155194. https://doi.org/10.1371/journal.pone.0155194.

24. Badley EM, Millstone DB, Perruccio AV. Back pain and co-occurring conditions: findings from a nationally representative sample. Spine (Phila Pa 1976). 2018(43):E935-e41. https://doi.org/10.1097/brs. 0000000000002590

25. Jimenez-Garcia R, Del Barrio JL, Hernandez-Barrera V, de Miguel-Díez J, Jimenez-Trujillo I, Martinez-Huedo MA, et al. Is there an association between diabetes and neck pain and lower back pain? Results of a population-based study. J Pain Res. 2018;11:1005-15. https://doi.org/10.2147/jpr.S158877.

26. Violan C, Foguet-Boreu Q, Flores-Mateo G, Salisbury C, Blom J, Freitag M, et al. Prevalence, determinants, and patterns of multimorbidity in primary care: a systematic review of observational studies. PLoS One. 2014;9: e102149. https://doi.org/10.1371/journal.pone.0102149.

27. Cassell A, Edwards D, Harshfield A, Rhodes K, Brimicombe J, Payne R, et al. The epidemiology of multimorbidity in primary care: a retrospective cohort study. Br J Gen Pract. 2018;68:e245-e51. https://doi.org/10.3399/bjgp18X695465.

28. van der Zee-Neuen A, Putrik P, Ramiro S, Keszei A, de Bie R, Chorus A, et al. Impact of chronic diseases and multimorbidity on health and health care costs: the additional role of musculoskeletal disorders. Arthritis Care Res (Hoboken). 2016;68:1823-31. https://doi.org/10.1002/acr.22913.

29. Foster NE, Anema JR, Cherkin D, Chou R, Cohen SP, Gross DP, et al. Prevention and treatment of low back pain: evidence, challenges, and promising directions. Lancet. 2018;391:2368-83. https://doi.org/10.1016/s014 0-6736(18)30489-6.

30. Almeida M, Saragiotto B, Richards B, Maher CG. Primary care management of non-specific low back pain: key messages from recent clinical guidelines. Med J Aust. 2018;208:272-5. https://doi.org/10.5694/mja17.01152.

31. Dennison L, Morrison L, Conway G, Yardley L. Opportunities and challenges for smartphone applications in supporting health behavior change: qualitative study. J Med Internet Res. 2013;15:e86. https://doi.org/10.2196/ jmir.2583. 
32. Zhao J, Freeman B, Li M. Can mobile phone apps influence people's health behavior change? An Evidence Review. J Med Internet Res. 2016;18:e287. https://doi.org/10.2196/jmir.5692.

33. Aitken MCB, Nass D. The growing value of digital health - evidence and impact on human health and the healthcare system. USA: IQVIA Institute for Human Data Science; 2017. https://www.iqvia.com/insights/the-iqviainstitute/reports/the-growing-value-of-digital-health. Accessed 31 Aug 2021

34. Nicholl BI, Sandal LF, Stochkendahl MJ, McCallum M, Suresh N, Vasseljen O, et al. Digital support interventions for the self-management of low back pain: a systematic review. J Med Internet Res. 2017;19:e179. https://doi.org/1 0.2196/jmir.7290.

35. Mork PJ, Bach K. A decision support system to enhance self-management of low back pain: protocol for the selfBACK project. JMIR Res Protoc. 2018;7: e167. https://doi.org/10.2196/resprot.9379.

36. Sandal LF, Stochkendahl MJ, Svendsen MJ, Wood K, Øverås CK, Nordstoga $A L$, et al. An app-delivered self-management program for people with low back pain: protocol for the selfBACK randomized controlled trial. JMIR Res Protoc. 2019;8:e14720. https://doi.org/10.21 96/14720.

37. Sandal LF, Bach K, Øverås CK, Svendsen MJ, Dalager T, Stejnicher Drongstrup Jensen J, et al. Effectiveness of app-delivered, tailored selfmanagement support for adults with lower back pain-related disability: a selfBACK randomized clinical trial. JAMA Intern Med. 2021. https://doi.org/1 0.1001/jamainternmed.2021.4097.

38. Kenning C, Fisher L, Bee P, Bower P, Coventry P. Primary care practitioner and patient understanding of the concepts of multimorbidity and selfmanagement: a qualitative study. SAGE Open Med. 2013;1: 2050312113510001. https://doi.org/10.1177/2050312113510001.

39. Gleadhill C, Kamper SJ, Lee H, Williams CM. Exploring integrated care for musculoskeletal and chronic health conditions. J Orthop Sports Phys Ther. 2021;51:264-8. https://doi.org/10.2519/jospt.2021.10428.

40. Krokstad S, Langhammer A, Hveem K, Holmen TL, Midthjell K, Stene TR, et al. Cohort profile: the HUNT study, Norway. Int J Epidemiol. 2013;42:96877. https://doi.org/10.1093/ije/dys095.

41. Kuorinka I, Jonsson B, Kilbom A, Vinterberg H, Biering-Sørensen F, Andersson G, et al. Standardised Nordic questionnaires for the analysis of musculoskeletal symptoms. Appl Ergon. 1987;18:233-7. https://doi.org/10.1 016/0003-6870(87)90010-x

42. Roland M, Fairbank J. The Roland-Morris Disability Questionnaire and the Oswestry Disability Questionnaire. Spine (Phila Pa 1976). 2000(25):3115-24. https://doi.org/10.1097/00007632-200012150-00006.

43. Smith SM, Wallace E, Salisbury C, Sasseville M, Bayliss E, Fortin M. A core outcome set for multimorbidity research (COSmm). Ann Fam Med. 2018;16: 132-8. https://doi.org/10.1370/afm.2178

44. van Hout B, Janssen MF, Feng YS, Kohlmann T, Busschbach J, Golicki D, et al. Interim scoring for the EQ-5D-5L: mapping the EQ-5D-5L to EQ-5D-3L value sets. Value Health. 2012;15:708-15. https://doi.org/10.1016/j.jval.2012. 02.008 .

45. Cohen S, Kamarck T, Mermelstein R. A global measure of perceived stress. J Health Soc Behav. 1983;24:385-96 PMID: 6668417.

46. Kroenke K, Spitzer RL, Williams JB. The PHQ-9: validity of a brief depression severity measure. J Gen Intern Med. 2001;16:606-13. https://doi.org/10.1046/ j.1525-1497.2001.016009606.x.

47. Brooks R. EuroQol: the current state of play. Health Policy. 1996;37:53-72. https://doi.org/10.1016/0168-8510(96)00822-6.

48. Hallegraeff JM, van der Schans CP, Krijnen WP, de Greef MH. Measurement of acute nonspecific low back pain perception in primary care physical therapy: reliability and validity of the brief illness perception questionnaire. BMC Musculoskelet Disord. 2013;14:53. https://doi.org/10.1186/1471-2474-14-53.

49. Nicholas MK. The pain self-efficacy questionnaire: taking pain into account. Eur J Pain. 2007;11:153-63. https://doi.org/10.1016/j.ejpain.2005.12.008.

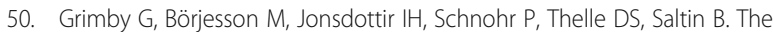
"Saltin-Grimby Physical Activity Level Scale" and its application to health research. Scand J Med Sci Sports 2015;25 Suppl 4:119-125. https://doi.org/1 $0.1111 /$ sms.12611.

51. Kamper SJ, Maher CG, Mackay G. Global rating of change scales: a review of strengths and weaknesses and considerations for design. J Man Manip Ther. 2009:17:163-70. https://doi.org/10.1179/jmt.2009.17.3.163.

52. Du S, Liu W, Cai S, Hu Y, Dong J. The efficacy of e-health in the selfmanagement of chronic low back pain: a meta-analysis. Int J Nurs Stud. 2020;106:103507. https://doi.org/10.1016/j.jjnurstu.2019.103507.
53. Mair FS, May CR. Thinking about the burden of treatment. Bmj. 2014;349: g6680. https://doi.org/10.1136/bmj.g6680.

54. Mangin D, Parascandalo J, Khudoyarova O, Agarwal G, Bismah V, Orr S. Multimorbidity, eHealth and implications for equity: a cross-sectional survey of patient perspectives on eHealth. BMJ Open. 2019;9:e023731. https://doi. org/10.1136/bmjopen-2018-023731.

55. Olander EK, Fletcher H, Williams S, Atkinson L, Turner A, French DP. What are the most effective techniques in changing obese individuals' physical activity self-efficacy and behaviour: a systematic review and meta-analysis. Int J Behav Nutr Phys Act. 2013;10:29. https://doi.org/10.1186/1479-5868-1 $0-29$.

56. Samdal GB, Eide GE, Barth T, Williams G, Meland E. Effective behaviour change techniques for physical activity and healthy eating in overweight and obese adults; systematic review and meta-regression analyses. Int J Behav Nutr Phys Act. 2017;14:42. https://doi.org/10.1186/s12966-017-0494-y.

57. Schroé H, Van Dyck D, De Paepe A, Poppe L, Loh WW, Verloigne M, et al. Which behaviour change techniques are effective to promote physical activity and reduce sedentary behaviour in adults: a factorial randomized trial of an e- and m-health intervention. Int J Behav Nutr Phys Act. 2020;17: 127. https://doi.org/10.1186/s12966-020-01001-x.

58. Svendsen MJ, Wood KW, Kyle J, Cooper K, Rasmussen CDN, Sandal LF, et al. Barriers and facilitators to patient uptake and utilisation of digital interventions for the self-management of low back pain: a systematic review of qualitative studies. BMJ Open. 2020;10:e038800. https://doi.org/1 0.1136/bmjopen-2020-038800.

59. Calderón-Larrañaga A, Vetrano DL, Ferrucci L, Mercer SW, Marengoni A, Onder $\mathrm{G}$, et al. Multimorbidity and functional impairment-bidirectional interplay, synergistic effects and common pathways. J Intern Med. 2019;285: 255-71. https://doi.org/10.1111/joim.12843.

60. Ryan A, Wallace E, O'Hara P, Smith SM. Multimorbidity and functional decline in community-dwelling adults: a systematic review. Health Qual Life Outcomes. 2015;13:168. https://doi.org/10.1186/s12955-015-0355-9.

61. Read JR, Sharpe L, Modini M, Dear BF. Multimorbidity and depression: a systematic review and meta-analysis. J Affect Disord. 2017;221:36-46. https://doi.org/10.1016/j.jad.2017.06.009.

62. Zemedikun DT, Gray LJ, Khunti K, Davies MJ, Dhalwani NN. Patterns of multimorbidity in middle-aged and older adults: an analysis of the UK biobank data. Mayo Clin Proc. 2018;93:857-66. https://doi.org/10.1016/j.ma yocp.2018.02.012.

63. Heikkinen J, Honkanen R, Williams L, Leung J, Rauma P, Quirk S, et al. Depressive disorders, anxiety disorders and subjective mental health in common musculoskeletal diseases: a review. Maturitas. 2019;127:18-25. https://doi.org/10.1016/..maturitas.2019.05.011.

64. Bayattork M, Jakobsen MD, Sundstrup E, Seidi F, Bay H, Andersen LL. Musculoskeletal pain in multiple body sites and work ability in the general working population: cross-sectional study among 10,000 wage earners. Scand J Pain. 2019:19:131-7. https://doi.org/10.1515/sjpain-2018-0304.

65. Sundstrup E, Jakobsen MD, Mortensen OS, Andersen LL. Joint association of multimorbidity and work ability with risk of long-term sickness absence: a prospective cohort study with register follow-up. Scand J Work Environ Health. 2017:43:146-54. https://doi.org/10.5271/sjweh.3620.

66. Andersén $H$, Kankaanranta $H$, Tuomisto LE, Piirilä P, Sovijärvi A, Langhammer A, et al. Multimorbidity in Finnish and Swedish speaking Finns; association with daily habits and socioeconomic status - Nordic EpiLung cross-sectional study. Prev Med Rep. 2021;22:101338. https://doi.org/10.1016/j.pmedr.2021.101338.

67. Wertli MM, Held U, Campello M, Schecter WS. Obesity is associated with more disability at presentation and after treatment in low back pain but not in neck pain: findings from the OIOC registry. BMC Musculoskelet Disord. 2016;17:140. https://doi.org/10.1186/s12891-016-0992-0.

68. Vinjerui KH, Boeckxstaens P, Douglas KA, Sund ER. Prevalence of multimorbidity with frailty and associations with socioeconomic position in an adult population: findings from the cross-sectional HUNT Study in Norway. BMJ Open. 2020;10:e035070. https://doi.org/10.1136/bmjopen-201 9-035070.

69. Pathirana TI, Jackson CA. Socioeconomic status and multimorbidity: a systematic review and meta-analysis. Aust N Z J Public Health. 2018;42:18694. https://doi.org/10.1111/1753-6405.12762.

70. Hanlon P, Hannigan L, Rodriguez-Perez J, Fischbacher C, Welton NJ, Dias S, et al. Representation of people with comorbidity and multimorbidity in clinical trials of novel drug therapies: an individual-level participant data analysis. BMC Med. 2019;17:201. https://doi.org/10.1186/s12916-019-1427-1. 
71. Smith SM, Soubhi H, Fortin M, Hudon C, O'Dowd T. Managing patients with multimorbidity: systematic review of interventions in primary care and community settings. Bmj. 2012;345:e5205. https://doi.org/10.1136/bmj.e5205.

72. Schäfer I, Kaduszkiewicz H, Wagner HO, Schön G, Scherer M, van den Bussche H. Reducing complexity: a visualisation of multimorbidity by combining disease clusters and triads. BMC Public Health. 2014;14:1285. https://doi.org/10.1186/1471-2458-14-1285.

73. Kongsted A, Hestbaek L, Kent P. How can latent trajectories of back pain be translated into defined subgroups? BMC Musculoskelet Disord. 2017;18:285. https://doi.org/10.1186/s12891-017-1644-8.

74. da Silva T, Mills K, Kongsted A, Maher CG, Hancock M. What is the personal impact of recurrences of low back pain? Subanalysis of an Inception Cohort Study. J Orthop Sports Phys Ther. 2020;50:294-300. https://doi.org/10.2519/ jospt.2020.9345.

75. Smith SM, Wallace E, O'Dowd T, Fortin M. Interventions for improving outcomes in patients with multimorbidity in primary care and community settings. Cochrane Database Syst Rev. 2021;1:Cd006560. https://doi.org/10.1 002/14651858.CD006560.pub4.

76. Sakib MN, Shooshtari S, St John P, Menec V. The prevalence of multimorbidity and associations with lifestyle factors among middle-aged Canadians: an analysis of Canadian Longitudinal Study on Aging data. BMC Public Health. 2019;19:243. https://doi.org/10.1186/s12889-019-6567-x.

77. Møller SP, Laursen B, Johannesen CK, Tolstrup JS, Schramm S. Patterns of multimorbidity and demographic profile of latent classes in a Danish population-A register-based study. PLoS One. 2020;15:e0237375. https://doi. org/10.1371/journal.pone.0237375.

78. Hanlon P, Nicholl BI, Jani BD, Lee D, McQueenie R, Mair FS. Frailty and prefrailty in middle-aged and older adults and its association with multimorbidity and mortality: a prospective analysis of 493737 UK Biobank participants. Lancet Public Health. 2018;3:e323-e32. https://doi.org/10.1016/ s2468-2667(18)30091-4.

79. Petermann-Rocha F, Hanlon P, Gray SR, Welsh P, Gill JMR, Foster H, et al. Comparison of two different frailty measurements and risk of hospitalisation or death from COVID-19: findings from UK Biobank. BMC Med. 2020;18:355. https://doi.org/10.1186/s12916-020-01822-4.

80. Rasmussen CDN, Svendsen MJ, Wood K, Nicholl BI, Mair FS, Sandal LF, et al. App-delivered self-management intervention trial selfBACK for people with low back pain: protocol for implementation and process evaluation. JMIR Res Protoc. 2020;9:e20308. https://doi.org/10.2196/20308.

\section{Publisher's Note}

Springer Nature remains neutral with regard to jurisdictional claims in published maps and institutional affiliations.

Ready to submit your research? Choose BMC and benefit from:

- fast, convenient online submission

- thorough peer review by experienced researchers in your field

- rapid publication on acceptance

- support for research data, including large and complex data types

- gold Open Access which fosters wider collaboration and increased citations

- maximum visibility for your research: over $100 \mathrm{M}$ website views per year

At BMC, research is always in progress.

Learn more biomedcentral.com/submissions 